\title{
Ecological Green Animal Building Existence Overview
}

\author{
Sheng Tan \\ Hongshan Forest Zoo, Nanjing
}

\begin{abstract}
Nowadays, in a world undergoing advanced technology, and growing wealth among people and the place they're living, animals begin to live into various zoos of all cities, which has become a means to protect animals and to maintain ecological balance. Building zoos, is not only for landscaping, but needs the integration of ecology and environment, so as to make rare and endangered animals, obtain a better living and growing space. In order to improve citizens' recreational and leisure quality, it is required to establish protection stations for rare and endangered animals, to implant necessary animal general knowledge and animal protection concept into the mind of children, and to reach environmental rationality and actual safeguarding standards on the earth, so as to educate the next generation, while reducing damages to ecological scope imperceptibly.

Keywords - Ecology, Green, Animal Building
\end{abstract}

\section{Excellent Garden Animal Buildings on Deep Level}

From this, it could be said that constructing excellent garden animal buildings to a deeper level, has indispensable living effect on the society as well as survival and growth of animals, ecological animal building, which is more scientific and economical, could lengthen animal life and optimize animal skin texture, help rather than damage ecological environment. Zoo building is a newly emerged branch at present, which basically adapts to animal's growth in a simple manner. In modern zoo undergoing mass construction of animal buildings, with further need on buildings for animals, simple and crude cages are not enough for the survival of animals. Except for optimal and elegant development, a more scientific ecological animal building scale is also required to be generated, and this shall not be simply called a zoo building while an "animal building" existing scientifically shall be designed in a complete and profound manner. For the need of animals is different from that of human beings, while profound animal growing habits and different needs of individual animals, reflect different functions of animal building, and such difference in the need of survival between human beings and animals, has resulted in the difference between residential building and animal building, i.e., muscle growth and survival mechanism of manchurian tiger living under snow environment tens of degrees below zero, are stronger than ecology and psychology of other animals, which is completely different from human beings. If we put it in a zoo building, the tiger will feel hard to survive, so it is required to establish an ecological "Animal Building" deliberately, making the tiger see local plants in North China, and form a ferocious and wide disposition, so as to extend its life. So it could be said that, subdividing residential buildings into clear and different ecological animal buildings which are profound and economical is necessary, besides, with people's further recognition on animals, animal buildings on a deeper level could be gradually improved to protect animals, to meet the need of establishing more and larger zoos in future, which are to become the home of animals for their longer survival.

Originally, animals are living in the wild place, which is relatively cold, so no air-conditioner is required, in this way, an entirely different insertion point between residential building and animal building was formed. Just keeping ambient temperature inside animal building at 15 degrees, could meet the demand, however, an air-conditioner temperature of about 20 degrees is required by residential building, so, it is required to equip a thermal-storing wall, which utilizes heat insulating materials inside the dual-layer wall, and it is measured that the thermal-storing wall could keep ambient temperature between zero degree to 15 degrees, so that animals could live in a relatively low temperature comfortably in winter, while it is the same in summer, the dual-layer thermal-storing wall could guarantee the temperature not too high, and buildings of this type could also be designed according to animal functions, which are entirely different from residential buildings.

Residential buildings could also be used to raise animals, however, buildings made according to animals' functional requirements are greatly different from residential buildings in all aspects, while animal buildings could be produced in an easier and cheaper manner, and simple single-storey monomer buildings could satisfy animals' psychological requirements, so, to use the title of animal building as a substitute for zoo building is appropriate, which could save materials, reduce cost, shorten construction period and reduce labor.

The planning of the home of animals, is to provide animals a more natural environment, and a design means to find out the most appropriate living conditions for animals among mountains or green lands, which is a method to optimize ecological animal territories and safe retreats.

\section{Animal Garden Building}

Animal garden building is an important barrier for the zoo to protect animals, which is closely related ecological garden, if we say ecological garden landscape system is a complicated ecological system, animal garden is at least a sub system under the "Grand Ecology". For it could only be built in the zoo without being accepted by people, so we can say that, with the development in area and number of the zoo in future, animal ecological system is sure to and needed to be built, while animal building will make faster and greater progress either. Actually, most gardens in the city are not entirely ecological, while ecological environment of the zoo is easier to be created 
and built. So beautiful a garden could become the home of animals, which possesses specific structural ecology, and eliminates ecological fragility and crushability etc., and become an urgent demand in modern zoo planning and green design.

Building is an industry consuming the largest quantities of natural resources, so secondary recycling and reuse of building materials, to make it into different materials in an environment-protective matter is in the pursuit of green ecology. Broadly speaking, green animal buildings reflects the sustainable ideology of cooperative development between human beings and natural environment, except for green largescaled residential buildings, ecological energy-saving buildings, animal buildings and ecological buildings could all be considered to possess the same concept with green buildings. Via practice, it is found out by people that building energysaving and animal building is either related or different from each other, for "animal building" is energy-saving in a natural way, which utilizes temperature difference in nature to adjust cage temperature, so as to reach the purpose of saving the use of "air conditioner", which shall be called an energy-saving building, and has solved the issue of over-high energy consumption within small buildings previously, created a healthy, comfortable and safe feature, as well as a new environmental-protective living space for animals, and established a natural and harmonious joint living mode. Commonness between animal buildings and green buildings is obvious, which has covered the content of all cycles such as saving energy, saving lands and secondary recycling of materials etc. related to construction activity.

Green building considers more about residential environment, as well as impact brought by damages to nature environment caused by human beings' living quality, while animal building pays more attention to natural ecology, for animals will not impact the growth of green environment.

Since the reform and opening up, construction ideas about zoo in China have emerged in an endless stream. Referring to luxury and abundance in foreign zoos, domestic private zoos have invested a great deal of funds, and established upright large-scaled buildings and gardens for raising animals. While under the call of protecting animals and rescuing rare and endangered animals, the interest to know about animals among tourists and children keeps rising increasingly, and the construction for animal cages and buildings which could breed animals well has prevailed in all large and middle-sized cities. However, these buildings are more like the pattern of residential building, which is not good for the growth of animals. So, in the trend of "Green Building" development, to design zoo buildings into environmentalfriendly ecological buildings has become a task of top priority. Constructing an energy-saving and comfortable green "Animal Building" system, which is safe and suitable for animals at a reasonable cost, will have important scientific significance and garden engineering value in the construction and development of energy-saving gardens as well as a harmonious society.

\section{Animal Building Has Greatly Saved Materials and Construction Procedures}

The concept of animal building, is to utilize normal materials, to construct a small building not similar to the scale of residential building for animals, in this way the concept and method for animal garden and building is formed, which has more beautiful shapes. Thus a different branch of residential building is generated, and it could be said that this is a kind of building unprecedented since the ancient times, for the need of simplicity and roughness of animals, this kind of building is certain to emerge. With respect to human's residence, for keeping warm and higher living comfortableness, people keep making walls and wainscots which need decoration repeatedly, while it is not the case for animals, the wild nature of fighting against nature and environment, makes animals able to live better without any decoration.

Nowadays, the word "animal garden" has become normal, if we plant a tree in the zoo, it is a kind of economical garden, which could not act as an exquisite garden as Suzhou Gardens, too root for which is animals do not need gardens with such a huge cost. Similarly, if we pile various trees together, its scale and pattern could only achieve a beautiful appearance, here, we arrange big trees and small trees according to animal scale, and further beautify according to inherent need for animal living, we could find that, zoo garden's manufacturing method and generating rules are clearly existing, so in this sense, no zoo garden with wonderful plants arranged or planted randomly, or piled could be regarded as an excellent one, in this way, if we plant trees according to animal characteristics at a large scale, just change the position of a certain tree slightly, the scale of a certain animal characteristics or an intangible potential shape could be generated, thus to generate the "Animal Garden". For example, we could design a tree in Crane Garden, and keep certain space aside, while plant an inclined dwarf plant, so an animal garden shaped like a crane, rather than garden without design fully planted with high and disordered plants is recommended, another example is the Hippo Pool, we could create two layers of plants along the pool, which is similar to the fat characteristics of hippo, with both layers right on the vertical sight line, we could see the fat feature etc., so environment-friendly building is an optimization under promotion at present.

\section{The Ideology of Animal Building}

Building is a life carrier, and a space provided for living, while building morphology possesses territoriality, ancient and modern nature. While animals as a vital body, are certain to possess a space serving for its survival, and such space is very spacious, which is an entity planned and designed by human beings for another kind of life - cages helping animal to develop in a more scientific manner.

Based on the "Green Building" system launched by the west as well as successfully building experience, we could solve animal living's healthy development issue, so as to form 
an animal environment integrating wild nature with the nature in a better way. Even without seeing animal buildings, only superior animal stone dwellings in mountainous areas could be seen, so as to present a particular animal building, is the basic motivation of this essay, exploring development of animals living in ecological mountain type building groups, is the purpose of this essay, regulating animal buildings as a relatively dwarf ecological mode, is the base and root of this essay, while exploring morphology and style of animal buildings in this mode, as well as different generations and further variation reflected by morphological structure of such buildings in future, is the goal of animal workers. The exploration on real motivation of ecological evolution of "animal building" as well as that of animal wild nature, could follow the progressing rules of development in science and technology, which means that buildings will follow the epoch's theory and practice to form its style, reflecting the generation and existence of animal building's morphology.

Such morphology also results in a perfect unification between building and art as well as ecology, which grasps numerous factors such as politics, economy, culture and tradition etc. involved in building in a comprehensive and considerate way.

Modern science, depending on concrete and steel, has turned stone and timber buildings from ancient times, into concrete buildings, while modern buildings in the west, depending on the application of new materials, new technologies and new models, has completed the reform on stone structures and classic buildings, however, it is contrary for buildings on animal aspect, while turning high buildings into natural small ones in the wild, has an effect of backing to nature, which happens to comply with ecological ideology in nowadays green building. In today's world, when standardization is required by world environment protection, people have standardized all buildings on the earth, which need to development towards green building, and further evolve into ecological buildings, and this is the "Environment" generated by green animal building accordingly, as well as the need for animal protecting and rescuing, which has cultivated the "animal building".

In a word, environment is an ecological system jointly required by both human beings and animals, which includes landform, vegetation, mountains and rivers, which is an extremely wide range. So whether New and relatively natural landforms generated by human beings' reformation on nature, would help wild nature of animals, for animals are growing in "small buildings", which is also appropriate, however, whether animals would recover wild nature better, when growing in the newly created green artificial environment? Zoo dwellings have its own locality, as well as inherent humanistic and historic features, so, whether such building cultural characteristics are coexistent in harmony, and how to achieve a better harmony? Some animals have characteristics of coexisting and living with human beings, under the impact of such cultural buildings, generating a more benign animal characteristic is an invisible growth strength hidden in animal bodies.

\section{Introduction to Animal Building}

Animal building is part of ecological building, which belongs to "green building" system, while animal building and plant garden are indivisible but correlated two parts, which complies with the thoughts of "Nature and Humanity" and "People Oriented", and marches towards a developing direction of getting more close to nature, while making efforts to integrate with the nature completely. "Nature and Humanity" indicates the concept of integrating the nature with human beings, which is also followed by animal building to connect with the nature, and to become a thought forming part of the nature, such all-in-one state, with progress in modern building as well as human beings' profound recognition on nature, makes people obtain a new recognition on the generation of animal science.

In this way, meeting existence demand of animal dwelling, has become a necessity for scientific development of animal buildings, and one part of ecological science, while animal building has also become a scientific building more ecological than "green building" system, which is smaller in volume, with large-scale wall surface greening and roof greening, as well as an end-to-end linked ecological nature system, free of waste and pollution, high-efficiency and harmonious building for animals, while natural and highly harmony between "animal building" and human environment, is one goal purchased by "Animal Building", which originates from ecology and possesses more advantageous ecology, optimizing ecological system, and is a different concept of animal building different from other buildings, an important ideology for animal building to obtain further development.

\section{Conclusion}

Requirements on engineering technology for animal buildings are not that high, but its economic ecology as well as art requirements have surpassed those of normal buildings, actually animal buildings are very simple, and artistry is very easy to establish and generate, with constant progressing of the society, new building materials and more environment protection requirements made animal building easier to find a new direction, while various schools of buildings, reflect few on animal buildings, although animal buildings look so easy superficially, large-scaled ecological operation in the overall forest areas has certain difficulty, besides, green ecology which is more energy-saving and water-saving is still not mature, which is high in cost and low in return, viewing from green building aspect, more difference is existing in animal buildings, for green buildings for human dwellings, new technologies of recycling large amounts of water and geothermal pump machinery are adopted, with numerous residents and huge benefits, however, secondary recycling water and geothermal energy used by animal buildings are relatively few, so a recycling machinery is adopted to generate geothermal energy, however, "animal building" is low in demand and usage, so 
there's certain difference in "green animal building" and residential "green building", which does not comply with the saying of people that all buildings of the green system are the same, so it is required to separately define animal building standards and residential building standards, to achieve a better saving effect, which is also a strength of animal buildings superior to residential buildings.

\section{References}

[1] Ecological House Design (English, German and Chinese) Collections on Garden Building Design Cases: Barbara Linz China Architecture \& Building Press.

[2] Roof Greening Building Design and Cases, China Architecture \& Building Press, Li Haiguan, Bai Yuxing and Gao Jianling.

[3] 1000 Design Skills of 100 Ecological Architects, translated by Liu Sichen and Yang Yitian, Electronic Industry Press.

[4] Low Carbon Ecological Space: Reconsideration of Cross-dimensional Planning ( $2^{\text {nd }}$ Edition), Dalian University of Technology Press Co., Ltd., Ye Da.
[5] Saving Building \& Saving Energy 50, Chief Editor Tu Fengxiang, China Architecture \& Building Press.

[6] Green Intelligent Building Technology, Ying Min and Zhang Wei, China Architecture \& Building Press.

[7] Environmental Bioremediation Technology and Cases, Chief Editor Li Suying, China Electric Power Press.

[8] 2015 China Sustainable Report, - Reshaping Ecological Environment Management System, Science Press.

[9] Ecological Urbanism, Chief Editor Tang Min and Zhang Pengwei, Huazhong University of Science and Technology Press.

[10] Modern Landscape Creativity, Zhou Wuzhong, Publishing House of Southeast University.

[11] Introduction to Architecture in the Remainder Times of Building Renewable Assets, Dalian University of Technology Press Co., Ltd., Chief Editor Matsubayashi Shuuichi.

[12] Solar Building Design, Xu Shen and Huang Jing, China Architecture \& Building Press.

[13] Urban Space Expansion Simulation and Ecological Control Line Optimized Early Warning Model Research, Chen Minghui and Li Xia, China Architecture \& Building Press. 